\title{
Classroom Interventions and Foreign Language Anxiety: A Systematic Review With Narrative Approach
}

\author{
Michiko Toyama* and Yoshitaka Yamazaki \\ Faculty of Business Administration, Bunkyo University, Tokyo, Japan
}

Experimental studies have developed, conducted, and evaluated classroom interventions for foreign language anxiety (FLA) reduction. However, various characteristics of those classroom interventions make it difficult to synthesize the findings and apply them to practice. We conducted what is, to the best of our knowledge, the first systematic review on educational interventions for FLA. Six criteria were established for inclusion of studies. Using English keywords, we identified 854 potentially eligible studies through ProQuest and Scopus, 40 of which were finally

\section{OPEN ACCESS}

Edited by:

Lawrence Jun Zhang,

University of Auckland, New Zealand

Reviewed by:

Jean-Marc Dewaele,

Birkbeck, University of London,

United Kingdom

Davinia M. Resurrección

Universidad Loyola Andalucía, Spain

Ting Sophia Xu,

The University of Auckland,

New Zealand

*Correspondence:

Michiko Toyama

toyama3@bunkyo.ac.jp

Specialty section:

This article was submitted to Educational Psychology,

a section of the journal

Frontiers in Psychology

Received: 05 October 2020 Accepted: 08 January 2021

Published: 09 February 2021

Citation:

Toyama M and Yamazaki Y (2021) Classroom Interventions and Foreign Language Anxiety: A Systematic Review With Narrative Approach.

Front. Psychol. 12:614184.

doi: 10.3389/fpsyg.2021.614184 included. All included studies were published from 2007 to 2020. The studies differed in type of intervention, duration of intervention, and scale to measure FLA. Our systematic review resulted in seven features of classroom interventions, categorized as student-student interactions, student-teacher interactions, self-management, and mood boosters; we also categorized interventions as either individual or interactional.

Keywords: anxiety reduction, experimental studies, educational intervention, learning environment, foreign language classroom anxiety, interactions

\section{INTRODUCTION}

A second language, which is often referred to as L2, is a language that is not a person's native language. The term refers to any language (also a third or fourth language) learned after the native language(s) has been acquired. A second language is usually learned as a foreign language. Compared to native language acquisition, nonnative language learning is remarkably associated with emotions. Anxiety has been the most commonly studied emotion in the context of nonnative language learning (Dewaele and MacIntyre, 2014). The term foreign language anxiety (FLA) can be defined as "the worry and negative emotional reaction aroused when learning or using a second language" (MacIntyre, 1999, p. 27). Language teachers often observe learners struggling with physical signs of anxiety such as tense muscles, trembling, and dry throat (Oxford, 2017b). Researchers have found that FLA interferes with thoughts, communication, and learning (see a summary by MacIntyre, 2017) using situation-specific scales such as the Foreign Language Classroom Anxiety Scale (FLCAS; Horwitz et al., 1986). Moreover, FLA can wreck the best teaching techniques and render the most attractive material inadequate (Arnold and Brown, 1999). Several suggestions, such as creating a positive, friendly, and relaxed attitude toward students, have been made to improve L2 teaching (Young, 1990). Many learning techniques have also been suggested; these include relaxing, deep breathing, meditation, listening to soothing music, and making positive statements (Oxford, 1990), and activation of supportive emotions, beliefs, and attitudes toward L2 learning and use (Oxford, 2011). More recently, experimental studies to examine the 
effectiveness of these previously suggested methods have been conducted. The experimental data in such studies are rather controversial, and there is no general agreement about what aspects of L2 learning can be changed to control FLA. Therefore, in this article, we systematically reviewed experimental studies on FLA.

\section{Recognition of FLA and Suggestions to Control It Before 2000}

Researchers in the field of L2 education began to investigate linguistic and nonlinguistic correlates of FLA using the FLCAS. The literature has documented the relationship of FLA to low achievement in L2 listening, speaking, reading, and writing outcome scores (see a literature review by Horwitz, 2001 and meta-analyses by Zhang, 2019 and Botes et al., 2020), to detrimental cognition such as increased self-related beliefs (see an overview by MacIntyre, 2017), and to unfavorable social attitudes and behaviors, such as reduced linguistic self-confidence (see a summary by MacIntyre, 2017). Data from past studies suggest that effects of FLA can be "quite insidious" (Dewaele and MacIntyre, 2014, p. 238); therefore, the importance of coping with FLA is widely recognized. In fact, the pioneering study of Horwitz et al. (1986) on FLA, which led to development of the well-known FLCAS, involved students who specifically sought assistance in reducing L2 classroom anxiety from teachers and counselors. The authors pointed out the importance of L2 learners' recognizing, coping with, and overcoming this anxiety.

Before the 2000s, most studies made suggestions about classroom interventions that teachers could implement. For example, Horwitz et al. (1986) suggested specific techniques for teachers such as behavioral contracts, relaxation exercises, advice on effective language learning strategies, and journal keeping. Foss and Reitzel (1988) introduced rational emotive therapy to the field of L2 education. This brief psychotherapy is based on the assumption that irrational beliefs are the source of anxiety. Rational emotive therapy helps learners recognize their own selfdefeating, irrational beliefs and modify them to more realistic expectations to manage FLA. Koch and Terrell (1991) found pair/group work made their students feel more comfortable than did other activities and thus suggested separating the class into pairs or small groups to help students reduce FLA. Young (1990) recommended that L2 teachers create and maintain a positive, friendly, and relaxed attitude toward students based on her questionnaire results. Oxford (1990) proposed a set of learning tactics called affective strategies to help learners cope with emotional difficulties. Oxford's affective strategies include progressive (muscle) relaxation, meditation, use of music, making positive statements to oneself (often referred to as positive self-talk), and discussing one's feelings with someone.

\section{Empirical Studies on Controlling FLA After $\mathbf{2 0 0 0}$}

Since the 2000s, a variety of empirical studies on foreign language anxiety reduction (FLAR) have examined different methods, approaches, and contexts. For example, the study of Kondo and Yang (2004) with 202 Japanese undergraduates identified 70 tactics to cope with FLA and categorized them into five strategies. With a different sample of 60 students, Kondo and Yang (2004) further investigated the application of the five strategies, with preparation being used the most at $60.4 \%$, followed by resignation $(28.2 \%)$, positive thinking $(26.2 \%)$, relaxation $(11.9 \%)$, and peer seeking (11.4\%). However, they revealed insignificant correlations between FLA scores and frequency of use of the coping strategies. On the other hand, Kao and Craigie (2013) reported that greater use of a positive thinking strategy was related to a lower level of L2 classroom anxiety. Examining 145 distance learning students in the United Kingdom, Hauck and Hurd (2005) reported that 48 (37\%) used some strategies to deal with FLA. Among 11 strategies, the three used most frequently were active self-encouragement to take risks (87.5\%), use of positive self-talk (64.6\%), and imagining a friendly informal chat when speaking in front of others (35.4\%) (Hauck and Hurd, 2005). Moreover, Tsiplakides and Keramida (2009) conducted a qualitative case study with 15 students at a secondary school in Greece. They suggested that incorporating short-term project work could be effective for FLAR since it offers a nonthreatening learning environment. They also pointed out the importance of a supportive classroom atmosphere.

\section{Classroom Interventions for Controlling FLA}

In recent years, there has been increasing focus on the relationship between classroom interventions and FLA. Two types of approaches for this line of studies have been observed. One is computer-mediated communication (CMC) as a nontraditional approach. CMC has provided entirely different modalities of classroom interactions. It allows learners to communicate regardless of time or location. For instance, virtual reality, video chat, and voice chat, as employed in York et al.'s (2020) study, could reduce FLA. Another approach is the application of positive psychology (Dewaele et al., 2019; MacIntyre et al., 2019), which offers various interventions to boost positive emotions while alleviating anxiety (Oxford, 2017a). For instance, positive self-talk, as employed in Toyama and Yamazaki's (2019) study, can help anxious L2 learners "feel more confident in learning the new language" (Oxford, 1990, p. 143). Gregersen (2013) explained that positive psychology could be beneficial for L2 teachers and learners, who can capitalize on positive affect while mitigating the effect of negative emotions such as anxiety. Also, it is important to integrate linguistic and nonlinguistic aspects into L2 education (MacIntyre et al., 2019). Applying positive psychology interventions in class, L2 teachers should deal with learners' psychological and social aspects (i.e., well-beingness) in addition to linguistic knowledge and skills.

Experimental studies have developed and implemented classroom interventions and evaluated their impact on FLA reduction. However, the classroom interventions' various characteristics make it difficult to synthesize the findings and apply them to practice. Unfortunately, no previous study has systematically reviewed the various classroom experimental interventions related to FLAR. Teachers may wonder if there is any evidence that a particular FLAR method is effective, 
how it works, or what can be improved. They may want to know which intervention is the most appropriate for application in their classes. This lack of understanding poses a significant challenge to L2 research and education. Thus, we aimed to systematically review past experimental studies, focusing on various educational interventions and their influence on FLAR.

\section{Study Approach}

This study presents a systematic review of FLAR intervention studies with a narrative approach. A systematic review is a particular type of literature review (Siddaway et al., 2019) that involves "a clearly formulated question" and "uses systematic and explicit methods to identify, select, and critically appraise relevant research, and to collect and analyze data from the studies that are included in the review" (Cochrane Collaboration, 2003, as cited in Siddaway et al., 2019, p. 751). A narrative approach relies "primarily on the use of words and text to summarize and explain the findings"; this approach is considered helpful in "the initial stages of a review" (Popay et al., 2006, p. 5). Moreover, it can be used when the experimental and quasi-experimental studies included in the review are not sufficiently similar to allow a meta-analysis (Mays et al., 2005). We adopted a narrative approach to a systematic review in this study since we aimed to systematically and transparently collect quantitative studies that have used diverse methodologies and to offer a text-based synthesis and analysis rather than a statistical summary.

Since a systematic review allows us to replicate studies, our methodology using a systematic review is congruent with a direction based on the view of King and Mackey (2016). They illustrated the importance of replication studies in the field of applied linguistics. In the field of L2 learning and teaching, a systematic review with a descriptive or narrative presentation of findings can be seen in the study of Boo et al. (2015), who utilized databases and anthology chapters from 2005 to 2014 on L2 motivation. We also reviewed processes and strategies from several other studies that applied a systematic review with metaanalysis in the field-covering the relationships between FLA and achievement (Teimouri et al., 2019), between FLA and L2 performance (Zhang, 2019), and between FLCA and academic achievement (Botes et al., 2020).

In this study, the term foreign language anxiety is used to refer to "the worry and negative emotional reaction aroused when learning or using a second language" (MacIntyre, 1999, p. 27). The term educational intervention and classroom intervention are used to refer to any activity, strategy, or method used to teach a new skill. The terms experimental study and intervention study are used to refer to studies where researchers introduced an intervention, collected data, and observed the effects of the intervention. The terms FLAR interventions and FLAR methods are used to refer to any educational interventions related to FLA management.

The following sections present the methodology for the systematic review, highlight the trends and patterns that were revealed, and discuss the findings in connection with previous research.

\section{METHODOLOGY}

\section{Study Guideline}

To develop a process for a systematic review with a narrative approach, we relied mainly on four studies on systematic reviews from Siddaway et al. (2019); Jiménez et al. (2020), Pluye and Hong (2014), and Resurrección et al. (2014). The first study allowed us to develop a theoretical framework and process for a systematic review with a narrative approach, while the other three studies provided useful insight. Also, we followed the overall flow of PRISMA (Moher et al., 2009).

\section{Pilot Search}

Prior to the literature search, we performed a pilot search to gain initial insight on the output of the database system, gage our study's relevance, and help us develop appropriate inclusion and exclusion criteria when entering several search term candidates. The first and second authors of this study independently carried out a pilot search. For this pilot search, we used the keywords of "foreign language anxiety" AND "reduction" in a search of ProQuest. The database allowed us to select publications written in the English language, with no time boundary, and among the document/publication types of article, book chapter, and book. To determine publication type, we referred to the review study of Boo et al. (2015), which considered only publications from journals through a database search and reviewed book chapters of seven specific anthologies published in the past. This pilot search resulted in 51 studies that were considered to be a pool for potential literature for our study review purpose.

\section{Literature Search}

To find potential studies relevant to FLAR, we utilized five online databases: Scopus, Linguistics and Language Behavior Abstracts, PsycINFO, PsycArticles, and PTSDpubs. All databases except for Scopus were accessed via ProQuest, a platform for searching multiple databases across multiple disciplines. Searches were performed using the key term "foreign language anxiety" combined with ("AND") each of nine different secondary terms: "reduction," “reducing," “decrease," “decreasing," "lowering," "relieving," "relief," "alleviate," and "alleviating." Different forms of the same word (e.g., reduction and reducing) were used in an attempt to capture more articles. The search using the databases was conducted in mid February 2020, without time limitations among the publications of article, book chapter, and book in the English language, and was last updated on November 28,2020 . The first and second authors searched the databases independently and then confirmed whether their database search results were consistent.

\section{Inclusion and Exclusion Criteria}

To identify studies relevant to our research questions, we established six inclusion and exclusion criteria (Table 1). Included studies had to be intervention/experimental studies that used a scale relevant to FLA and presented quantitative results; systematic reviews and meta-analysis studies were excluded. The studies also had to be published in English as a journal article, 
TABLE 1 | Inclusion and exclusion criteria for review.

\begin{tabular}{|c|c|c|}
\hline Category & Inclusion criteria & Exclusion criteria \\
\hline 1. Study type & $\begin{array}{l}\text { Intervention/experimental } \\
\text { study }\end{array}$ & $\begin{array}{l}\text { Not intervention/ } \\
\text { experimental study }\end{array}$ \\
\hline 2. Study design & $\begin{array}{l}\text { Not systematic review or } \\
\text { meta-analysis }\end{array}$ & $\begin{array}{l}\text { Systematic review or } \\
\text { meta-analysis }\end{array}$ \\
\hline 3. Scale description & $\begin{array}{l}\text { Description/explanation of } \\
\text { scale relevant to FLA }\end{array}$ & $\begin{array}{l}\text { No } \\
\text { description/explanation } \\
\text { of scale }\end{array}$ \\
\hline 4. Result description & Quantitative results & Only qualitative results \\
\hline 5. Language & English & Not English \\
\hline 6. Publication type & $\begin{array}{l}\text { Article, book chapter, or } \\
\text { book }\end{array}$ & $\begin{array}{l}\text { Conference } \\
\text { proceedings, } \\
\text { university-specific } \\
\text { publication, working } \\
\text { paper, or } \\
\text { dissertation/thesis }\end{array}$ \\
\hline
\end{tabular}

FLA, foreign language anxiety.

book chapter, or book. Studies from the search results that did not meet these conditions were excluded from our review.

\section{Data Extraction}

The first database search identified 854 potentially eligible studies: 367 from ProQuest and 487 from Scopus. After removal of 338 duplicates, 516 potential studies were reviewed by title and abstract. The first and second authors analyzed the titles and abstracts separately. Then, they discussed results of reviewed studies and excluded 428 studies, leading to 88 studies to assess for eligibility based on full-text analysis. These two authors read the 88 full-text studies and independently analyzed whether they met the inclusion/exclusion criteria. After independent analysis, the authors discussed results to determine studies to be included in the synthesis. The full-text analysis led to the elimination of 48 studies: 28 because of lack of intervention/experimental study, 14 because of lack of FLA measure or unclear measures, one because it was not in a targeted publication, one because it was not an English publication, and four because of lack of availability of full text. Accordingly, 40 studies were included in the synthesis based on the criteria. Figure 1 reviews the flow of data extraction using the PRISMA diagram (Moher et al., 2009).

Various characteristics of the included studies were documented, including publication information (author and year of publication), study design characteristics (sample, intervention type, duration, and scale), and statistical characteristics (analytical methods and key results). Table 2 lists the included studies with their characteristics and FLAR interventions.

\section{RESULTS}

\section{Synthesis of Results}

Our database search and extraction identified 40 studies that assessed FLAR intervention. Before analyzing key features of effective FLAR intervention, we conducted descriptive analysis to summarize trends of FLAR interventions in the literature.
As depicted in Table 3, the earliest experimental FLAR research identified in this study was published in 2007, and the latest in November 2020. The number of publications on FLAR interventions increased over that time period, except for 2019. Additionally, since FLAR was already being addressed in the late 1980s and early 1990s (see Foss and Reitzel, 1988; Young, 1992), the total number of 40 publications was smaller than might have been expected. Studies came out of 17 countries/regions, but half were performed in four countries/regions: Taiwan $(n=7)$, Turkey $(n=5)$, China $(n=4)$, and Iran $(n=4)$; further, over two-thirds $(n=28)$ were conducted in East and West Asia.

Foreign language anxiety reduction interventions were more common in higher education institutions than in primary schools. As shown in Table 3, most studies took place in undergraduate schools $(n=27)$ followed by high schools $(n=7)$. Three-fourths of the FLAR intervention studies had sample sizes smaller than 100; 18 had 10-49 students, and 12 had 5099 students. One study, that of Alrabai (2015), involved 468 students. More than two-thirds of the studies had a control group ( $n=27)$, while one-third had only an experimental group $(n=13)$. The shortest duration of the interventions was $1 \mathrm{~h}$ or less, while the longest was 9 months, equivalent to 36 weeks. Almost one-third took place between 1 and 9 weeks $(n=12)$ or between 10 and 19 weeks $(n=14)$. Twelve different scales were used to measure the effectiveness of interventions. Among the 40 studies, the FLCAS (Horwitz et al., 1986) was most widely used $(n=23)$. Another popular scale was the Second Language Writing Anxiety Inventory (SLWAI) (Cheng, 2004) $(n=5)$. One explanation for the popularity of these scales is that L2 speaking and writing are more likely to cause FLA than reading and listening are. Other scales similar to the FLCAS were developed or modified among this group of studies, including the English Classroom Anxiety Scale (ECAS) (Liao and Wang, 2015), English Classroom Speaking Anxiety Scale (ECSAS) (Tang, 2016), English Language Classroom Anxiety Scale (ELCAS) (Liu, 2009), and Foreign Language Classroom Anxiety Questionnaire (FLCAQ) (Young, 1990; Woodrow, 2006). The use of those scales also indicated a focus on L2 speaking anxiety. Sixty percent of the studies reported Cronbach's alphas $(n=24)$.

With regard to statistical methods of the FLAR intervention studies, almost all studies conducted statistical tests, while one study performed descriptive analysis (Chen and Lee, 2011) and one did not clearly present a statistical method (Jahin, 2012). Over one-third of studies used a paired $t$-test $(n=14)$ followed by an independent $t$-test $(n=9)$, Wilcoxon signed rank test $(n=7)$, and repeated analysis of variance $(n=5)$.

Several interventions included more than one task/tactic/tool for L2 education; thus, we use the term feature to differentiate the types of reviewed interventions. We found seven features: CMC, student-student communication, teacher-student communication, performance, strategy instruction, counseling and training, and mood boosters. The most common features were related to communication: CMC such as text chat and online forums (Arnold, 2007), student-student interactions such as peer feedback (Bailey and Cassidy, 2019), and teacher-student interaction such as portfolio assessment (Nosratinia and Abdi, 2017). Some interventions included both student-student and 


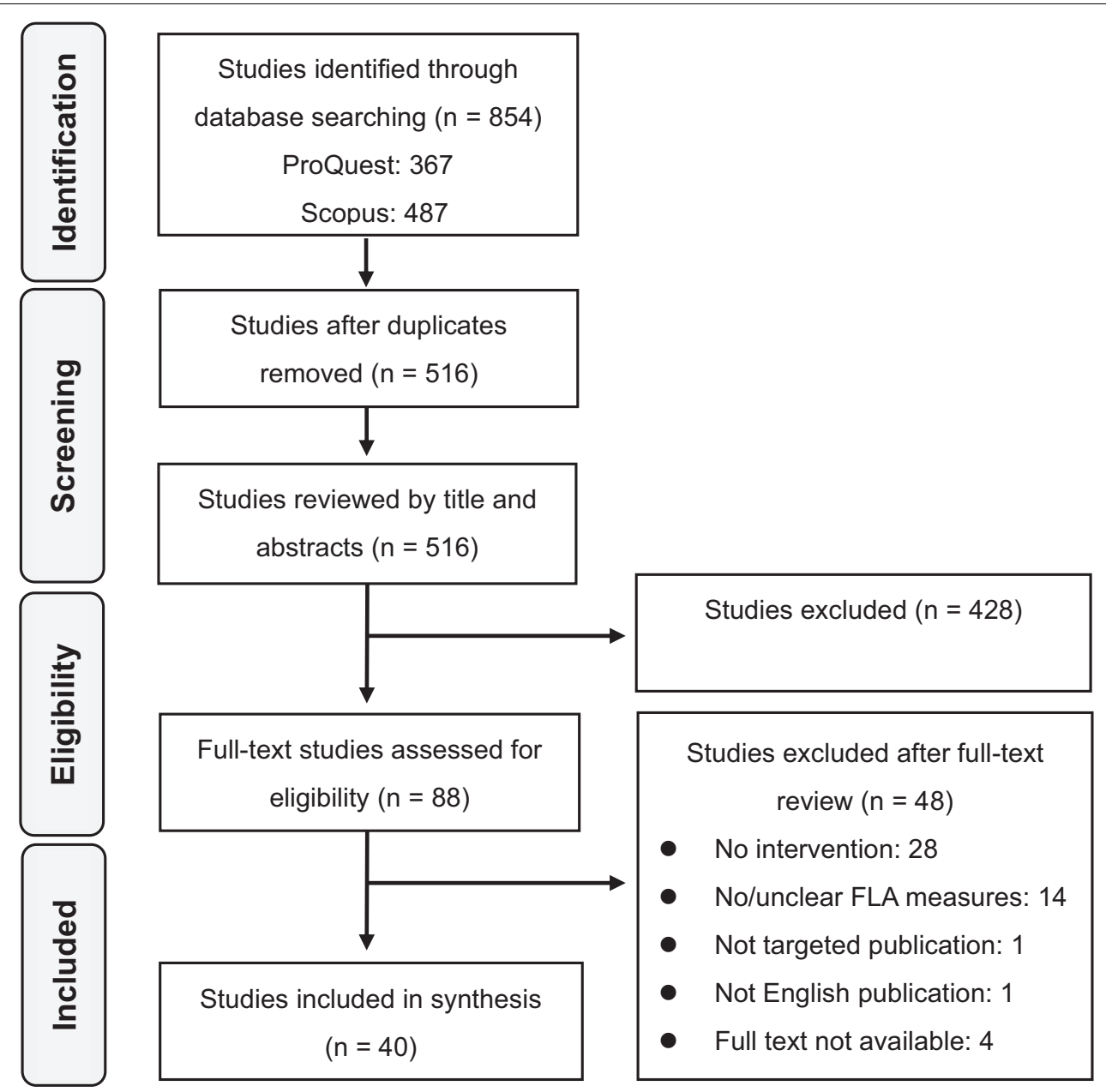

FIGURE 1 | PRISMA flowchart of the FLAR studies included.

teacher-student interactions (Liao and Wang, 2015; Chen et al., 2016; Tang, 2016), and some had both CMC and studentstudent/teacher-student communication (e.g., $\mathrm{Ku}$ and Chen, 2015). Our review further found learner-internal features of FLAR interventions. Five studies used performance such as drama (Sağlamel and Kayaoğlu, 2013; Galante, 2018; Uştuk and Aydin, 2018; Kwiecień-Niedziela et al., 2020) or digital storytelling (Liu et al., 2018), five involved strategies (Alrabai, 2015; Mostafavi and Vahdany, 2016; He, 2017; Tsiriotakis et al., 2017; Bielak, 2018), four interventions used counseling and training (Abood and Abu-Melhim, 2015; Kralova et al., 2017, 2018; Toyama and Yamazaki, 2019), and four used mood boosters such as meditation (Scida and Jones, 2017), music (Shimbo, 2008), gaming (Wei et al., 2018), and web-based L2 exercises (Bashori et al., 2020).

\section{Types of Interventions}

The educational interventions reviewed in this article have the potential to affect individual (learner-internal) and interactional dimensions in L2 learning. Figure 2 shows the types of educational interventions. The types on the left are based on our review results. Examples of interventions are listed on the right. Those that can affect more than one dimension are placed between the two dimensions. Each major type (individual and interactional) is divided into two more subtypes: selfmanagement, mood-boosters, student-student interactions, and teacher-student interactions (Figure 2). The following sections summarize the main results obtained with each type and subtype.

\section{The Individual Type}

As shown in Figure 2, the reviewed interventions that can change learners' individual dimensions are categorized into two groups: self-management and mood boosters. This distinction is useful because some methods (e.g., affective strategy instruction) help learners develop their self-management capabilities, while others assist mood improvement (e.g., music and gaming). The following paragraphs first compare and contrast various methods developing L2 learners' self-management skills and then analyze those improving learners' mood.

Our review found two interventions that have an effect on individuals' self-management capabilities. Use of strategies was frequently reported, but strategy interventions were highly 
TABLE 2 | Descriptive classification of FLAR intervention characteristics.

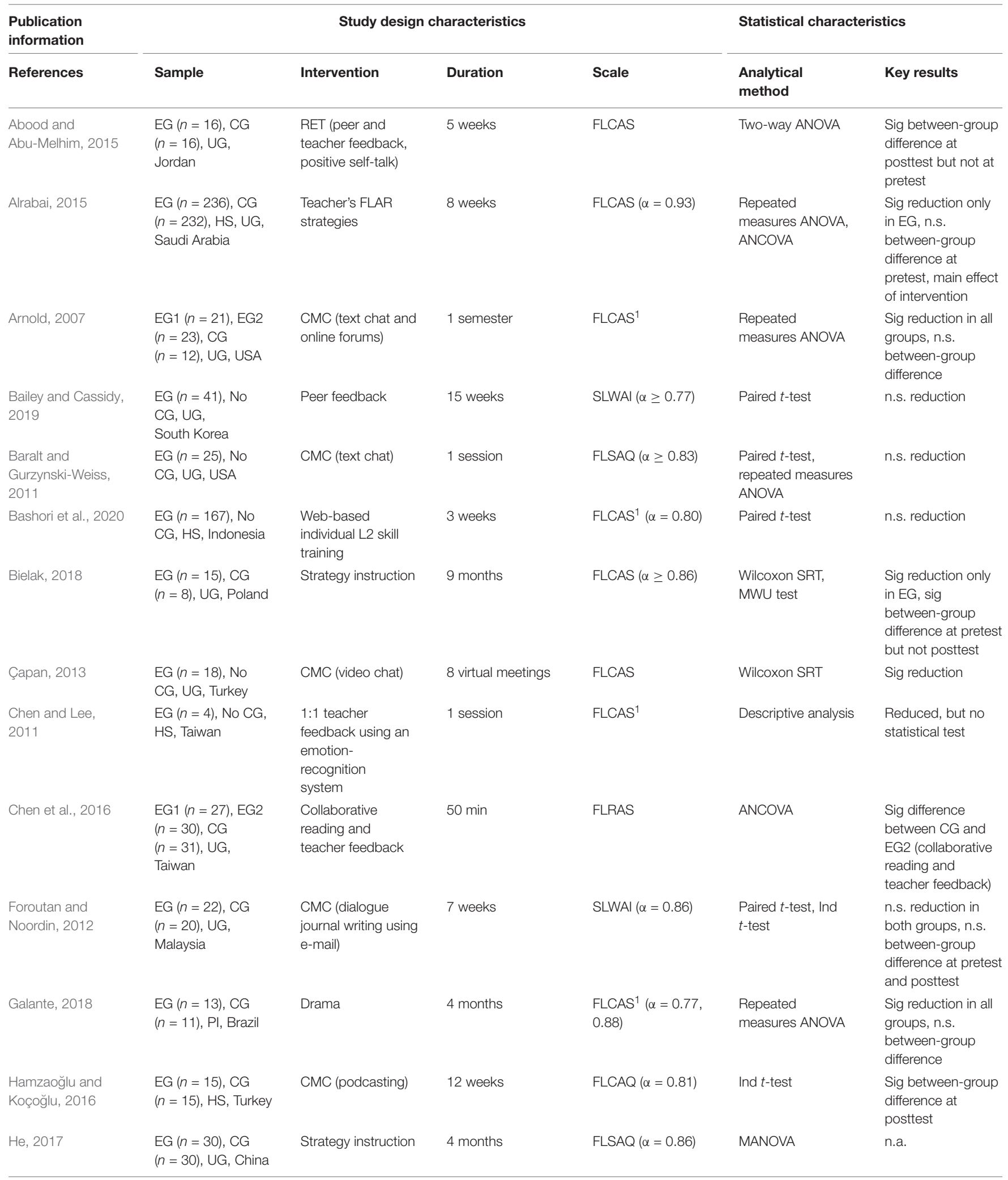


TABLE 2 | Continued

\begin{tabular}{|c|c|c|c|c|c|c|}
\hline \multirow{2}{*}{$\begin{array}{l}\begin{array}{l}\text { Publication } \\
\text { information }\end{array} \\
\text { References }\end{array}$} & \multirow[b]{2}{*}{ Sample } & \multicolumn{2}{|c|}{ Study design characteristics } & \multirow[b]{2}{*}{ Scale } & \multicolumn{2}{|c|}{ Statistical characteristics } \\
\hline & & Intervention & Duration & & $\begin{array}{l}\text { Analytical } \\
\text { method }\end{array}$ & Key results \\
\hline Jahin, 2012 & $\begin{array}{l}\text { EG }(n=20), C G \\
(n=20), \cup G \\
\text { Saudi Arabia }\end{array}$ & $\begin{array}{l}\text { Peer reviewing in } \\
\text { writing }\end{array}$ & 14 weeks & SLWAI $(\alpha=0.89)$ & n.a. & $\begin{array}{l}\text { Sig reduction only } \\
\text { in EG, sig } \\
\text { between-group } \\
\text { difference at } \\
\text { posttest }\end{array}$ \\
\hline Jin et al., 2020 & $\begin{array}{l}\mathrm{EG}(n=20), \mathrm{CG} \\
(n=22), \mathrm{UG}, \text { China }\end{array}$ & $\begin{array}{l}\text { Student behavioral } \\
\text { contracts }\end{array}$ & 1 week & $\operatorname{ECAS}(\alpha \geq 0.83)$ & Two-way ANOVA & $\begin{array}{l}\text { Sig main effect of } \\
\text { time, n.s. main } \\
\text { effect of group, sig } \\
\text { interaction effect of } \\
\text { group and time }\end{array}$ \\
\hline Kralova et al., 2018 & $\begin{array}{l}\mathrm{EG}(n=30), \mathrm{CG} \\
(n=33), \mathrm{UG}, \\
\text { Slovakia }\end{array}$ & $\begin{array}{l}\text { Psychosocial } \\
\text { training }\end{array}$ & 24 weeks & FLPAS & Wilcoxon SRT/RST & $\begin{array}{l}\text { Sig reduction in } \\
\text { both groups, sig } \\
\text { between-group } \\
\text { difference at } \\
\text { posttest but not at } \\
\text { pretest }\end{array}$ \\
\hline Kralova et al., 2017 & $\begin{array}{l}\mathrm{EG}(n=22), \mathrm{CG} \\
(n=46), \cup \mathrm{G}, \\
\text { Slovakia }\end{array}$ & $\begin{array}{l}\text { Psychosocial } \\
\text { training }\end{array}$ & 12 weeks & FLPAQ & Wilcoxon SRT/RST & $\begin{array}{l}\text { Sig reduction in } \\
\text { both groups, sig } \\
\text { between-group } \\
\text { difference at } \\
\text { posttest but not at } \\
\text { pretest }\end{array}$ \\
\hline Kruk, 2016 & $\begin{array}{l}\mathrm{EG}(n=13), \mathrm{CG} \\
(n=14), \mathrm{HS} \\
\text { Poland }\end{array}$ & CMC (virtual world) & 1 week & FLCAS $(\alpha \geq 0.89)$ & $\begin{array}{l}\text { Wilcoxon SRT, } \\
\text { MWU test }\end{array}$ & $\begin{array}{l}\text { n.s. between-group } \\
\text { difference, n.s. } \\
\text { reduction in both } \\
\text { groups }\end{array}$ \\
\hline Ku and Chen, 2015 & $\begin{array}{l}\text { EG }(n=49) \text {, No } \\
\text { CG, HS, Taiwan }\end{array}$ & $\begin{array}{l}\text { CMC (collaborative } \\
\text { learning with } \\
\text { Google Wiki) }\end{array}$ & 3 days & TCLAl $(\alpha=0.91)$ & Paired $t$-test & Sig reduction \\
\hline Liu et al., 2018 & $\begin{array}{l}\mathrm{EG}(n=27), \mathrm{CG} \\
(n=28), \mathrm{PS}, \text { Taiwan }\end{array}$ & $\begin{array}{l}\text { Performance } \\
\text { (cooperative digital } \\
\text { storytelling) }\end{array}$ & 10 weeks & FLCAS & ANCOVA & $\begin{array}{l}\text { Sig reduction only } \\
\text { in EG, sig } \\
\text { between-group } \\
\text { difference at } \\
\text { posttest }\end{array}$ \\
\hline $\begin{array}{l}\text { Melchor-Couto, } \\
2017\end{array}$ & $\begin{array}{l}\mathrm{EG}(n=7), \mathrm{CG} \\
(n=7), \mathrm{UG}, \\
\text { United Kingdom }\end{array}$ & CMC (virtual world) & 4 sessions & FLCAS $^{1}$ & ANOVA & $\begin{array}{l}\text { Sig difference in } E G \\
\text { between sessions, } \\
\text { but n.s. in CG }\end{array}$ \\
\hline $\begin{array}{l}\text { Mostafavi and } \\
\text { Vahdany, } 2016\end{array}$ & $\begin{array}{l}\mathrm{EG}(n=30), \mathrm{CG} \\
(n=30), \mathrm{HS}, \text { Iran }\end{array}$ & Strategy instruction & 6 weeks & $\operatorname{FLCAS}^{1}(\alpha=0.87)$ & $\begin{array}{l}\text { Paired } t \text {-test, Ind } \\
t \text {-test }\end{array}$ & $\begin{array}{l}\text { n.s. reduction in } \\
\text { both groups, n.s. } \\
\text { between-group } \\
\text { difference at } \\
\text { pretest, but EG had } \\
\text { higher scores than } \\
\text { CG at posttest }\end{array}$ \\
\hline $\begin{array}{l}\text { Nosratinia and } \\
\text { Abdi, } 2017\end{array}$ & $\begin{array}{l}E G(n=35), C G \\
(n=35), \cup G \text {, Iran }\end{array}$ & $\begin{array}{l}\text { Portfolio } \\
\text { assessment }\end{array}$ & 5 weeks & $\operatorname{FLCAS~}(\alpha=0.70)$ & Ind $t$-test & $\begin{array}{l}\text { Sig between-group } \\
\text { difference at } \\
\text { posttest }\end{array}$ \\
\hline $\begin{array}{l}\text { Sağlamel and } \\
\text { Kayaoğlu, } 2013\end{array}$ & $\begin{array}{l}\text { EG }(n=22), \text { No } \\
\text { CG, UG, Turkey }\end{array}$ & Creative drama & 6 weeks & $\operatorname{FLCAS}^{1}(\alpha=0.90)$ & Wilcoxon SRT & Sig reduction \\
\hline
\end{tabular}


TABLE 2 | Continued

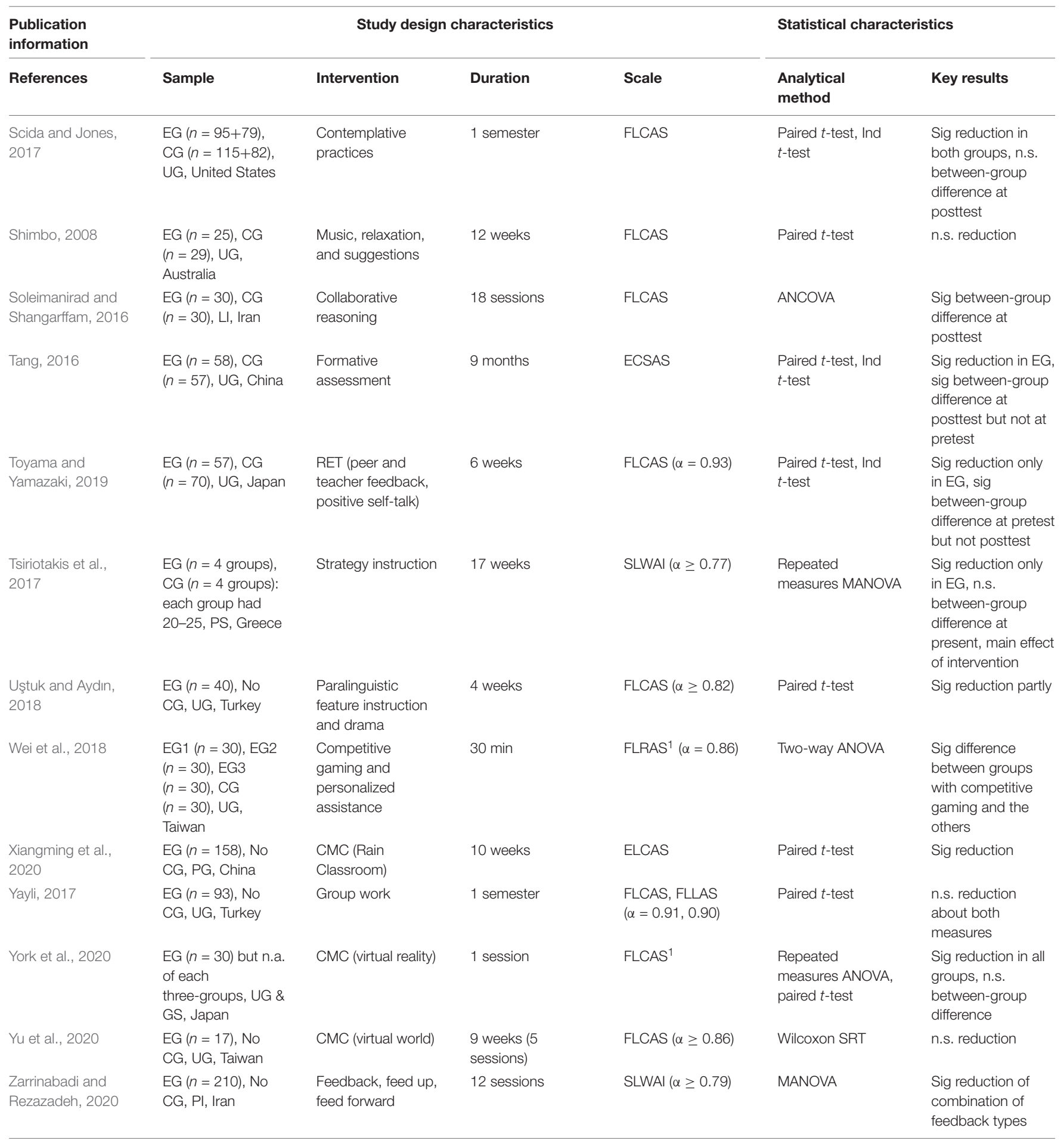

1:1, one-to-one; ANCOVA, analysis of covariance; ANOVA, analysis of variance; CG, control group; CMC, computer-mediated communication; ECAS, English Classroom Anxiety Scale; ECSAS, English Classroom Speaking Anxiety Scale; ELCAS, English Language Classroom Anxiety Scale; EG, experimental group; FLAR, foreign language anxiety reduction; FLCAQ, Foreign Language Classroom Anxiety Questionnaire; FLCAS, Foreign Language Classroom Anxiety Scale; FLCAS ${ }^{1}$, a modified version of FLCAS; FLLAS, Foreign Language Listening Anxiety Scale; FLPAQ, Foreign Language Pronunciation Anxiety Questionnaire; FLPAS, Foreign Language Pronunciation Scale; FLRAS ${ }^{1}$, a modified version of Foreign Language Reading Anxiety Scale; FLSAQ, Foreign Language State Anxiety Questionnaire; GS, graduate school; HS, high school; Ind, independent; LI, language institute; LMS, learning management system; MANOVA, multivariate analysis of variance; MS, middle school; MWU, Mann-Whitney U; n.a., not applicable or insufficient description; n.s., not significant; PI, private institute; PG, postgraduates; PS, primary school students; RET, rational emotive therapy; RST, rank sum test; sig., significant; SLWAI, Second Language Writing Anxiety Inventory; SRT, signed rank test; TCLAl, Transnational Collaborative Learning Anxiety; UG, undergraduates; $\alpha$, Cronbach's alpha. 
TABLE 3 | Characteristics of the 40 studies included in the systematic review.

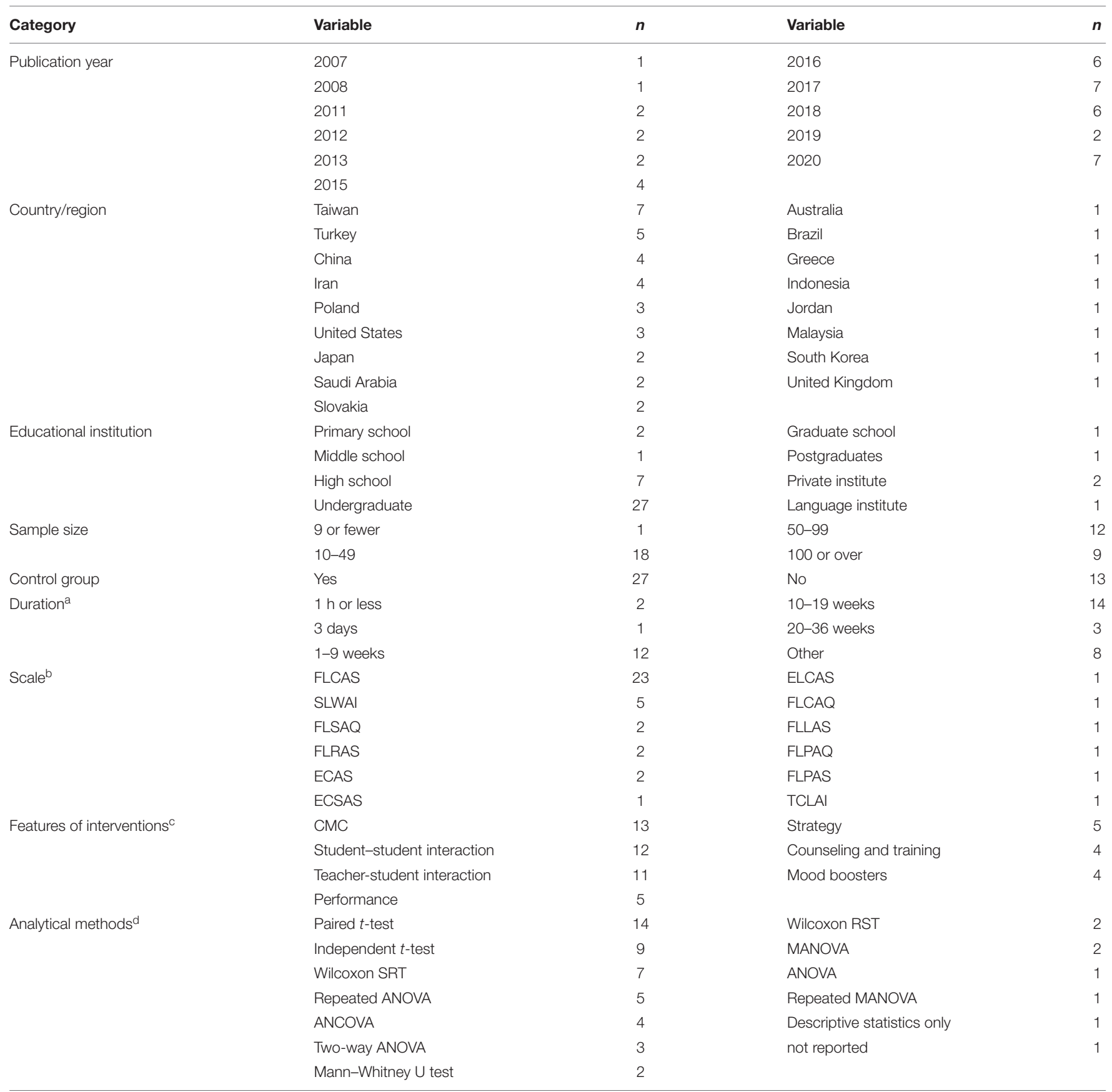

ane semester was converted to 17 weeks. Nine months was converted to 36 weeks.

${ }^{b}$ Cronbach's alphas reported: 11 for FLCAS, 5 for SLWAI, 2 for ECAS, 2 for FLSAQ, and 1 each for FLCAQ, FLLAS, FLRAS, and TCLAI.

cSome studies used more than one intervention.

dSome studies used more than one method.

CMC, computer-mediated communication; ECAS, English Classroom Anxiety Scale; ECSAS, English Classroom Speaking Anxiety Scale; ELCAS, English Language Classroom Anxiety Scale; FLCAQ, Foreign Language Classroom Anxiety Questionnaire; FLCAS, Foreign Language Classroom Anxiety Scale; FLLAS, Foreign Language Listening Anxiety Scale; FLPAQ, Foreign Language Pronunciation Anxiety Questionnaire; FLPAS, Foreign Language Pronunciation Scale; FLRAS, Foreign Language Reading Anxiety Scale; FLSAQ, Foreign Language State Anxiety Questionnaire; SLWAl, Second Language Writing Anxiety Inventory; TCLAl, Transnational Collaborative Learning Anxiety.

heterogeneous. Some studies used Oxford (1990, 2011, 2017a) affective strategies that target $\mathrm{L} 2$ learners who experience negative effects of anxiety. By teaching affective strategies, language teachers can help learners develop their emotion management capabilities (Oxford, 2015). Bielak (2018) confirmed the effectiveness of affective strategy instruction with significantly 


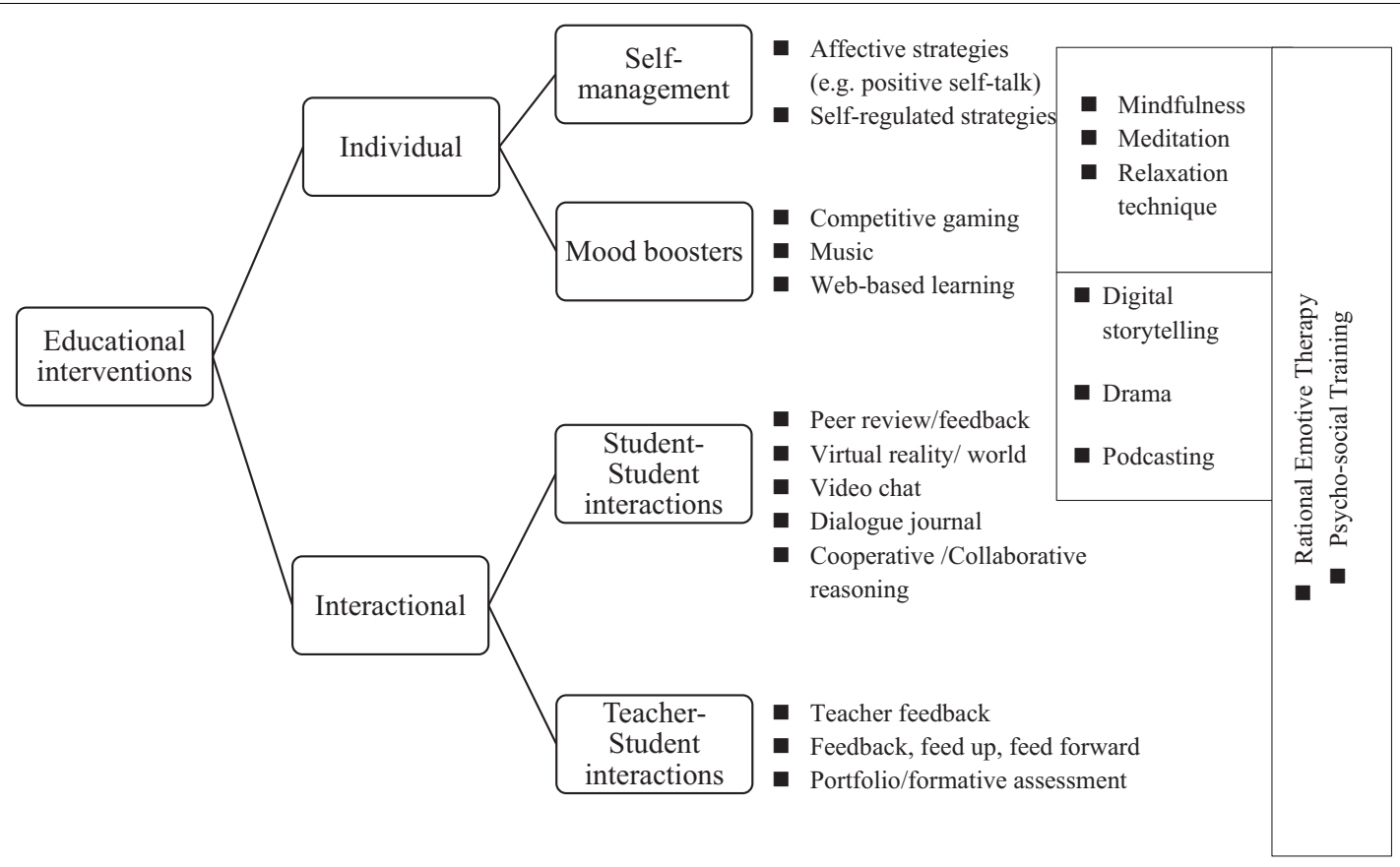

FIGURE 2 | Types of foreign language anxiety reduction (FLAR) methods.

lower level of FLCA and more frequent and wider range of affective strategy use in the intervention condition. Mostafavi and Vahdany (2016) also reported the effectiveness of affective strategy instruction; however, the FLCAS scores of their intervention group somehow increased. Positive self-talk or "self-encouragement via positive statements" (Oxford, 1990, p. 142), as employed in Toyama and Yamazaki's (2019) study, is often considered a type of affective strategy. Toyama and Yamazaki (2019) used positive self-talk in the framework of rational emotive therapy and reported within- and betweengroup decreases in FLA. Tsiriotakis et al. (2017) implemented Graham and Harris's (1989) self-regulated strategy development, which aims to enhance affective, behavioral, and cognitive aspects of learning, and confirmed its effectiveness in reducing L2 writing anxiety as well as improving L2 skills. The others used a range of questionnaire survey-based strategies (He, 2017) or an assorted set of strategies taken from previous literature (Alrabai, 2015). A criticism of these studies is that they used a range of strategies for teachers and learners, and thus it is difficult to determine which strategy or which set of strategies was effective in FLA reduction.

As shown in Figure 2, contemplative practices and relaxation were placed between self-management and mood boosters since these methods work on thoughts and feelings. Results concerning contemplative practices (Scida and Jones, 2017) and relaxation (Shimbo, 2008) remain unclear. Psychologists have demonstrated the effects of contemplative practices such as mindfulness and meditation on physical and psychological health and well-being (see a review by Dorjee, 2016). Similarly, relaxation techniques reduce frustration and boost confidence (MacIntyre and Gregersen, 2012). However, these methods require future research in L2 education, as their effectiveness has not yet been confirmed statistically.

Our review also found several interventions that have an effect on the individual's mood. The use of music, competitive gaming, and web-based learning can be categorized as mood boosters, since these interventions have the potential to bring enjoyment, concentration, or excitement to L2 learners. However, the results were contradictory. While competitive gaming was reported to be effective in reducing FLA (Wei et al., 2018), the effectiveness of music (Shimbo, 2008) and web-based learning (Bashori et al., 2020) remain unclear.

\section{The Interactional Type}

Interactional interventions can be categorized into two groups: student-student and teacher-student interactions (Figure 2). Different studies employed an intervention to enhance both types of interactions and confirmed a significant between-group difference at posttest (Liao and Wang, 2015; Chen et al., 2016; Soleimanirad and Shangarffam, 2016; Tang, 2016). Jin et al. (2020) used a behavioral contract method where L2 learners signed a contract to commit to speaking in L2 class and confirmed a significant decrease in the intervention condition compared to the control group. Enhancing only student-student communication may not result in FLA reduction. For instance, peer feedback (Bailey and Cassidy, 2019) and group work (Yayli, 2017) were not effective for FLAR. The effectiveness of peer reviewing in L2 writing (Jahin, 2012) remained unclear because of insufficient statistical reports. In contrast, a focus on teacherstudent interaction enhancement is likely to be effective. Portfolio assessment, which enhances teacher-student communication, was found effective in reducing more FLA in comparison with 
a non-interventional group (Nosratinia and Abdi, 2017). Teacher feedback, feed up, and feed forward (Zarrinabadi and Rezazadeh, 2020) also resulted in a significant reduction in FLA, but the study had no comparison group. Promoting teacher feedback using an emotion-recognition system decreased FLA (Chen and Lee, 2011); however, the authors did not report statistical results.

Results of CMC remain unclear. Only two studies compared intervention and nonintervention groups and found a significant difference. Hamzaoğlu and Koçoğlu (2016) used a podcasting intervention and showed that the intervention group achieved not only lower anxiety but also higher speaking test scores. Use of the virtual world called Second Life for weekly conversation training for 4 weeks also resulted in a significant FLA decrease only in the intervention condition (Melchor-Couto, 2017). In the virtual world, interactions are achieved through avatars. Two other studies with the virtual world, however, did not find any significant differences: Second Life in Yu et al. (2020) and Yoowalk for grammar practice in speaking for two classes within a week (Kruk, 2016). York et al. (2020) used a virtual reality where users could interact using their avatars, voice and paralinguistic cues in gestures. In their experiment, participants completed a spot-the-difference task in three different synchronous CMC modes: voice chat, video chat, and virtual reality with voice chat. All three modes successfully reduced FLA, but no betweengroup difference was found. We found many studies with various CMC interventions designed to enhance student-student and/or teacher-student interactions. In Arnold's (2007) experiment, student-student interactions through text chat, online forums, and face-to-face interaction were compared. FLA was reduced in all groups, but no between-group difference was found. Using email for dialogue journal writing to enhance student-student interactions (Foroutan and Noordin, 2012) and synchronous text chat between a teacher and a student (Baralt and GurzynskiWeiss, 2011) were not effective in reducing FLA. Many other studies did not use a control group. Çapan (2013) enhanced interactions between students in different institutions using video chat and showed a significantly lower FLCAS scores after the intervention, but there was no comparison group. Xiangming et al. (2020) used Rain Classroom, a mobile application for teaching and learning, and found not only a significant decrease in ELCAS scores but also significant increases in L2 speaking, listening, and writing test scores after the intervention. Although they did not have a control group, they succeeded in improving both linguistic and nonlinguistic aspects in L2 learning. Use of Google Wiki for cross-cultural collaborative learning was also effective in reducing FLA, but there was no control group (Ku and Chen, 2015).

\section{Performance Type}

Some methods reviewed in this study improved both individual and interactional dimensions in L2 learning. Interventions including performance such as drama or digital storytelling are grouped into this type. We found four studies with the drama technique (Sağlamel and Kayaoğlu, 2013; Galante, 2018; Uştuk and Aydın, 2018; Kwiecień-Niedziela et al., 2020) and one with cooperative digital storytelling (Liu et al., 2018). The effectiveness of drama intervention remains unclear. None of the drama intervention studies showed a significant within- and betweengroup difference; we found only partial evidence. In contrast, the study of Liu et al. (2018) is an excellent example of an intervention that can boost personal mood and enhance student-student communication. They hypothesized that students working cooperatively would gain greater knowledge and less FLA than those working individually. Both cooperative and individualistic learning groups engaged in a digital storytelling task in their study. They showed that the cooperative learning group achieved not only lower anxiety but also higher test scores than the individualistic learning group did at the posttest. Surprisingly, those engaged in the digital storytelling task individually increased their FLCA level by the end of the experiment. Podcasting (Hamzaoğlu and Koçoğlu, 2016) described in the previous section concerning CMC also includes a performance phase. In Figure 2, these methods are placed between individual and interactional. The preparation and performance of these activities can be a mood booster. In addition, the preparation or practice phase of drama or cooperative storytelling enhances student-student interactions.

\section{Training/Counseling Type}

Training/counseling interventions can also improve both individual and interactional dimensions of L2 learning. In fact, they are designed to improve student-student interactions through peer feedback and teacher-student interaction through debriefing and feedback. Applying rational emotive therapy combined with positive self-talk, two studies (Abood and AbuMelhim, 2015; Toyama and Yamazaki, 2019) reported successful decrease in FLA.

Use of psychosocial training (Kralova et al., 2017, 2018) also resulted in significantly more FLA reduction in the intervention condition. Kralova et al.'s (2017) psychosocial training was conducted in smaller groups with a psychologist and placed importance on both teacher-student and student-student interactions. The psychologist's goal was to create a supportive environment and an atmosphere that generates psychological trust and helps learners cope with stressful situations, while the learners' goal was to develop social abilities through sharing ideas on various topics (e.g., who I am, we are all different, communication, emotions, how to resolve conflicts). In their experiment, both intervention and control groups received L2 pronunciation training while only the intervention group received psychosocial training. The results revealed that the intervention group achieved not only higher pronunciation scores but also lower anxiety. Perhaps one criticism of the study is that requiring a psychologist to lead this training reduces the feasibility of its application in L2 education. In Figure 2, these interventions are placed in a box extending perpendicularly, showing their multiple purposes.

\section{DISCUSSION}

The present review has focused on the association between various types of educational interventions and FLA reduction in order to clarify the state of the field and suggest future directions. 
To the best of our knowledge, this is the first systematic review specifically examining the types and effectiveness of educational interventions on FLA.

Consistent with previous suggestions, affective strategy instruction improved FLA, as measured by the FLCAS (Bielak, 2018). Affective strategies (Oxford, 1990, 2011, 2017a) target L2 learners who experience negative effects of anxiety and help them create positive emotions, beliefs, and attitudes and stay motivated (Oxford, 2011). By teaching affective strategies, language teachers can help learners develop their emotion management capabilities (Oxford, 2015). The cognitive effects of FLA, such as increased self-related cognition (e.g., thoughts of failure and self-deprecating thoughts) (MacIntyre, 2017), can also be managed by means of affective strategies. Strategy instruction can provide anxious L2 learners with "readily sharable techniques and strategies" (Oxford, 2015, p. 385). Therefore, affective strategy instruction can strengthen learners' ability to cope with FLA, which may affect emotional, cognitive, and attitudinal dimensions in learning. Affective strategy instruction is also in line with Dewaele and MacIntyre (2014, 2016, 2019) suggestion that the main cause of FLA is the learner rather than the teacher. Nevertheless, our systematic review identified only two intervention studies that examined the effectiveness of affective strategy instruction, and only one of them could show a significant FLA reduction in the intervention condition. Moreover, the affective strategies in Oxford (1990) were updated in Oxford (2011) to include eight meta-affective strategies such as Monitoring Affect. While Bielak (2018) taught both affective and meta-affective strategies to students, Mostafavi and Vahdany (2016) used only the affective strategies in Oxford (1990). Therefore, further work is needed to compare the effect of affective strategy instruction and meta-affective strategy instruction, respectively.

We also found interventions that combined two or three methods. Rational emotive therapy (Foss and Reitzel, 1988) combined with positive self-talk or "self-encouragement via positive statements" (Oxford, 1990, p. 142) and peer and teacher feedback improved FLA, as measured by the FLCAS (Abood and Abu-Melhim, 2015; Toyama and Yamazaki, 2019). This brief therapy helps learners recognize their own irrational beliefs as a source of anxiety and modify them to more realistic expectations to manage FLA. In Toyama and Yamazaki's (2019) intervention, L2 learners were instructed to have positive images of themselves being more confident during positive self-talk. Such instruction or assistance seems necessary for the FLAR process. Their qualitative analysis revealed that participants attempted to "change their negative feelings, perceptions, beliefs, and behaviors" (Toyama and Yamazaki, 2019, p. 9) during positive self-talk activity, and their level of FLA was successfully lowered. This combination can be implemented without much work on instructors (i.e., training or much practice before implementation). Similarly, psychosocial training combined with L2 pronunciation training improved FLA, as measured by the Foreign Language Pronunciation Anxiety Scale (FLPAS) (Kralova et al., 2017). An instructor's positive, patient, and relaxed attitude (Young, 1990) along with social-skill and pronunciation skill development realized in their psychosocial training should have played a critical role in FLAR. Such multipurpose interventions are placed between the types in Figure 2. Note that this figure is in line with MacIntyre's (2017) comment: “Anxiety is influenced by internal physiological processes, cognition, and emotional states along with the demands of the situation and the presence of other people, among other things, considered over multiple timescales. Anxiety has both internal and social dimensions" (p. 34).

While reviewing the literature in this field, we identified some interventions combining cooperative learning with digital storytelling (Liu et al., 2018), Google Wiki editing (Ku and Chen, 2015), or reasoning exercises (Soleimanirad and Shangarffam, 2016) to be effective in reducing FLA. Cooperative learning enhances student-student interactions and thus changes the classroom environment, which plays a crucial role in the experience of L2 enjoyment and anxiety, confirming previous research (Dewaele and MacIntyre, 2014). As we found that group work by itself could not reduce anxiety (Yayli, 2017), the combination of cooperative learning with a task outside of course materials is recommended. Another important finding is that a focus on teacher-student interaction enhancement is likely to be effective. Portfolio assessment (Nosratinia and Abdi, 2017) and teacher feedback, feed up, and feed forward methods (Zarrinabadi and Rezazadeh, 2020) that enhanced teacher-student communication could reduce more FLA in comparison with a non-interventional group. These findings confirmed Aida's (1994) suggestion that L2 teachers had the important role in lessening classroom tension and in creating a friendly, supportive atmosphere that could help reduce FLA. These methods can be included as a complement or as a main task in L2 skill development processes for reducing FLA. They are considered feasible and realistic in L2 educational contexts.

Interaction "involves teachers, learners, and others acting upon each other and consciously or unconsciously interpreting those actions" (Oxford, 1997, p. 444). Foreign language education is characterized by being interactive; however, the interactive FLAR interventions allow learners to communicate with others even more frequently and in meaningful ways. In other words, these interventions can change interactions in L2 education. Many interventions reviewed in this article utilized smaller groups or pairs, which tend to engender a better atmosphere, more individual use of L2, and the creation of closer social bonds with peers (Dewaele and MacIntyre, 2014). We assume that the quantity and quality of oral and written interactions were enhanced by the classroom environment (i.e., a nonthreatening atmosphere and pair/group work) created by the teacher/researcher conducting these interventions. Learners with high FLA tend to distrust social situations in which they must interact in L2; however, anxious learners in the successful interventions could begin to trust the social situations requiring use of L2 through meaningful interactions with teachers, peers, and others. Their FLA level lowered because the fear of being laughed at, embarrassed, or misunderstood, which are considered to be social causes of FLA (MacIntyre, 2017), had been removed through frequent and meaningful interactions. These findings are in agreement with previous suggestions that creating a nonthreatening classroom and community through 
a friendly climate (Lucas, 1984; Crookall and Oxford, 1991) or focusing on authentic communication (Phillips, 1998) are effective in reducing FLA.

Furthermore, the present review found controversial evidence concerning the effectiveness of CMC on FLA. Despite similarity among studies (e.g., tasks using virtual world), the results of the intervention studies on FLA were inconsistent. Use of a virtual world system called Second Life (Melchor-Couto, 2017) resulted in a significant FLA decrease after the intervention while the same system used in $\mathrm{Yu}$ et al. (2020) did not. Another virtual world system called Yoowalk for grammar practice in speaking (Kruk, 2016) also did not reduce FLA. Results of text chat intervention were also inconsistent. Use of text chat in Arnold (2007) successfully reduced FLA, while synchronous text chat in Baralt and Gurzynski-Weiss (2011) did not. Further experimental research is necessary to confirm the effectiveness of various types of CMC.

Finally, this review has highlighted a need for further research for interventions including performance such as drama. This type of interventions has a high potential of bringing positive feelings at the individual level and a positive atmosphere to classrooms and thus need to be studied with a sufficient number of participants and a sufficient duration, using appropriate procedures and methods of analyses to examine their effectiveness. Additional research is needed to provide more objective evidence regarding what works, in what situations, and why. Creating a positive atmosphere in classrooms, promoting positive feelings in learners, and helping learners develop their skills to manage feelings and beliefs are valued, and there are indications that some methods are effective.

\section{LIMITATIONS}

Our analysis was dependent on information published only in English, so we do not claim that our dataset is fully comprehensive. Moreover, due to the complex nature of FLA interventions, it was not always straightforward to determine the category of a particular method. In spite of the study's limitations, the tables and figures presented in this article are robust enough to reflect accurate and meaningful tendencies.

\section{REFERENCES}

Abood, M. H., and Abu-Melhim, M. H. (2015). Examining the effect of group counseling in reducing anxiety for Jordanian EFL learners. J. Lang. Teach. Res. 6, 749-757. doi: 10.17507/jltr.0604.06

Aida, Y. (1994). Examination of Horwitz, Horwitz, and Cope's construct of foreign language anxiety: the case of students of Japanese. Mod. Lang. J. 78, 155-168. doi: 10.1111/j.1540-4781.1994.tb02026.x

Alrabai, F. (2015). The influence of teachers' anxiety-reducing strategies on learners' foreign language anxiety. Innov. Lang. Learn. Teach. 9, 163-190. doi: $10.1080 / 17501229.2014 .890203$

Arnold, J., and Brown, H. (1999). "A map of the terrain," in Affect in Language Learning, ed. J. Arnold (Cambridge: Cambridge University Press), 1-24.

Arnold, N. (2007). Reducing foreign language communication apprehension with computer-mediated communication: a preliminary study. System 35, 469-486. doi: 10.10/1016/j.system.2007.07.002

\section{CONCLUSION}

This study provides the first systematic review of various classroom interventions and their influence on FLA. It revealed that experimental FLAR intervention studies have been fueled by the trends of (1) reporting scale reliability, (2) including a control group, (3) improving the length of interventions, (4) having an appropriate number of participants, (5) using mean-based statistical analysis, and (6) reporting both withingroup and between-group differences. This information can be useful in developing a new intervention and conducting experimental research.

The review showed that FLAR interventions can affect individual and interactional dimensions. Awareness of these different ways to approach FLAR interventions can assist L2 researchers and teachers in establishing specific goals and strategies for their environment. We hope that this study's systematic organization of information on FLAR methods can begin to provide answers for L2 learners who need to develop anxiety management skills and to educators who are working to create a low-anxiety learning environment and bring a positive atmosphere to classrooms.

Finally, based on the results of this review, we recommend the cooperative digital storytelling approach by Liu et al. (2018) for L2 educators since this method can (1) enhance both linguistic and nonlinguistic (i.e., psychological and social) skills, (2) stimulate imagination, creativity, enthusiasm, and joy, and (3) change both individual and interactional dimensions in L2 learning, without being too demanding of teachers.

\section{AUTHOR CONTRIBUTIONS}

MT and YY conducted the systematic review and contributed to the final manuscript.

\section{FUNDING}

This work was supported by JSPS KAKENHI Grant Number JP17K02938.

Bailey, D., and Cassidy, R. (2019). Online peer feedback tasks: training for improved L2 writing proficiency, anxiety reduction, and language learning strategies. CALL-EJ 20, 70-88.

Baralt, M., and Gurzynski-Weiss, L. (2011). Comparing learners' state anxiety during task-based interaction in computer-mediated and face-to-face communication. Lang. Teach. Res. 15, 201-229. doi: 10.1177/0265532210388717

Bashori, M., van Hout, R., Strik, H., and Cucchiarini, C. (2020). Web-based language learning and speaking anxiety. Comp. Assist. Lang. Learn. 1-32. doi: 10.1080/09588221.2020.1770293 [Epub ahead of print].

Bielak, J. (2018). "The effect of strategy instruction on english majors' use of affective strategies and anxiety levels," in Challenges of Second and Foreign Language Education in a Global World, eds M. Pawlak and A. MystkowskaWiertelak (Cham: Springer International Publishing), 227-250.

Boo, Z., Dörnyei, Z., and Ryan, S. (2015). L2 motivation research 2005-2014: understanding a publication surge and a changing landscape. System 55, 145157. doi: 10.1016/j.system.2015.10.006 
Botes, E., Dewaele, J.-M., and Greiff, S. (2020). The foreign language classroom anxiety scale and academic achievement: an overview of the prevailing literature and a meta-analysis. J. Psychol. Lang. Learn. 2, 26-56.

Çapan, S. A. (2013). An online alternative to alleviate communication apprehension. Int. J. Appl. Ling. English Literat. 2, 202-210. doi: 10.7575/aiac. ijalel.v.2n.3p.202

Chen, C., and Lee, T. (2011). Emotion recognition and communication for reducing second-language speaking anxiety in a web-based one-to-one synchronous learning environment. Br. J. Educ. Technol. 42, 417-440. doi: 10.1111/j.1467-8535.2009.01035x

Chen, C.-M., Wang, J.-Y., Chen, Y.-T., and Wu, J.-H. (2016). Forecasting reading anxiety for promoting English-language reading performance based on reading annotation behavior. Interactive Learn. Environ. 24, 681-705. doi: 10.1080/ 10494820.2014.917107

Cheng, Y.-S. (2004). A measure of second language writing anxiety: scale development and preliminary validation. J. Second Lang. Writ. 13, 313-335. doi: $10.1016 /$ j.jslw.2004.07.001

Cochrane Collaboration (2003). Glossary. London: Cochrane Collaboration.

Crookall, D., and Oxford, R. (1991). "Dealing with anxiety: some practical activities for language learners and teacher trainees," in Language Anxiety: From Theory and Research to Classroom Implications, eds E. K. Horwitz and D. J. Young (Englewood Cliffs, NJ: Prentice-Hall), 141-150.

Dewaele, J. M., Chen, X., Padilla, A. M., and Lake, J. (2019). The flowering of positive psychology in foreign/second language teaching and acquisition research. Front. Psychol. 10:2128. doi: 10.3389/fpsyg.2019.02128

Dewaele, J.-M., and MacIntyre, P. (2016). "Foreign language enjoyment and foreign language classroom anxiety. The right and left feet of FL learning?", in Positive Psychology in SLA, eds P. MacIntyre, T. Gregersen, and S. Mercer (Bristol: Multilingual Matters), 215-236.

Dewaele, J.-M., and MacIntyre, P. D. (2014). The two faces of Janus? Anxiety and enjoyment in the foreign language classroom. Stud. Sec. Lang. Learn. Teach. 4, 237-274. doi: 10.14746/ssllt.2014.4.2.5

Dewaele, J.-M., and MacIntyre, P. D. (2019). “The predictive power of multicultural personality traits, learner and teacher variables on foreign language enjoyment and anxiety," in Evidence-Based Second Language Pedagogy: A Collection of Instructed Second Language Acquisition Studies, eds M. Sato and S. Loewen (London: Routledge), 263-286.

Dorjee, D. (2016). Defining contemplative science: the metacognitive selfregulatory capacity of the mind, context of meditation practice and modes of existential awareness. Front. Psychol. 7:1788. doi: 10.3389/fpsyg.2016.01788

Foroutan, M., and Noordin, N. (2012). Effect of dialogue journal writing through the use of conventional tools and e-mail on writing anxiety in the ESL context. Eng. Lang. Teach. 5, 10-19. doi: 10.5539/let.v5n1p10

Foss, K. A., and Reitzel, A. C. (1988). A relational model for managing second language anxiety. TESOL Q. 22, 437-454. doi: 10.2307/3587288

Galante, A. (2018). Drama for L2 speaking and language anxiety: evidence from Brazilian EFL learners. RELC J. 49, 273-289. doi: 10.1177/0033688217746205

Graham, S., and Harris, K. R. (1989). Components analysis of cognitive strategy instruction: effects on learning disabled students' composition and self-efficacy. . Educ. Psychol. 81, 353-361. doi: 10.1037/0022-0663.81.3.353

Gregersen, T. (2013). "Language learning vibes: what, why and how to capitalize for positive affect," in The Affective Dimension in Second Language Acquisition, eds D. Gabryś-Barker and J. Bielska (Bristol: Multilingual Matters), 89-98.

Hamzaoğlu, H., and Koçoğlu, Z. (2016). The application of podcasting as an instructional tool to improve Turkish EFL learners' speaking anxiety. Educ. Media Int. 53, 313-326. doi: 10.1080/09523987.2016.1254889

Hauck, M., and Hurd, S. (2005). Exploring the link between language anxiety and learner self-management in open language learning contexts. Eur. J. Open Dist. e-Learn. 2005, 1-12.

He, D. (2017). How to cope with foreign language speaking anxiety effectively? The case of university students in China. Elect. J. For. Lang. Teach. 14, 159-174.

Horwitz, E. K. (2001). Language anxiety and achievement. Annu. Rev. Appl. Ling. 21, 112-126. doi: 10.1017/S0267190501000071

Horwitz, E. K., Horwitz, M. B., and Cope, J. (1986). Foreign language classroom anxiety. Modern Lang. J. 70, 125-132. doi: 10.1111/j.1540-4781.1986.tb05256.x

Jahin, J. H. (2012). The effect of peer reviewing on writing apprehension and essay writing ability of prospective EFL teachers. Austr. J. Teach. Educ. 37, 60-84. doi: 10.14221 /ajte. $2012 \mathrm{v} 37 \mathrm{n} 11.3$
Jiménez, Ó, Ramos, N. S., González-Moraleda, Á, and Resurreción, D. M. (2020). Brief mindfulness-based interventions in a laboratory context: a systematic review of randomized controlled trials. Mindfulness 11, 849-861. doi: 10.1007/ s12671-020-01320-x

Jin, Y., Zhang, L. J., and MacIntyre, P. D. (2020). Contracting students for the reduction of foreign language classroom anxiety: an approach nurturing positive mindsets and behaviors. Front. Psychol. 11:1471. doi: 10.3389/fpsyg. 2020.01471

Kao, P. C., and Craigie, P. (2013). Coping strategies of Taiwanese university students as predictors of English language learning anxiety. Soc. Behav. Pers. 41, 411-420. doi: 10.2224/sbp.2013.41.3.411

King, K. A., and Mackey, A. (2016). Research methodology in second language studies: trend, concerns, and new directions. Modern Lang. J. 100, 209-227. doi: $10.111 / \bmod 1.12309$

Koch, A., and Terrell, T. D. (1991). "Affective reactions of foreign language students to natural approach activities and teaching techniques," in Language Anxiety: From Theory and Research to Classroom Implications, eds E. K. Horwitz and D. J. Young (Englewood Cliffs, NJ: Prentice-Hall), $109-126$.

Kondo, D. S., and Yang, L. Y. (2004). Strategies for coping with language anxiety: the case of students of English in Japan. ELT J. 58, 258-365. doi: 10.1093/elt/58. 3.258

Kralova, Z., Skorvagova, E., Tirpakova, A., and Markehova, D. (2017). Reducing student teachers' foreign language pronunciation anxiety through psycho-social training. System 65, 49-60. doi: 10.1016/j.system.2017.01.001

Kralova, Z., Tirpakova, A., and Skorvagova, E. (2018). Personality factors and foreign language pronunciation anxiety. Eur. J. Contemp. Educ. 7, 728-740. doi: 10.13187/ejced.2018.4.728

Kruk, M. (2016). The impact of using internet resources and browser-based virtual worlds on the level of foreign language anxiety. CALL Open 2, 103-121. doi: 10.3726/978-3-653-06756-9

$\mathrm{Ku}, \mathrm{D} . \mathrm{T}$., and Chen, N. L. (2015). Influence of wiki participation on transnational collaboration learning anxiety in middle school students. Internet Res. 25, 794-810. doi: 10.1108/IntR-05-2014-0142

Kwiecień-Niedziela, E., Polok, K., and Mala, E. (2020). Drama techniques as correlators of the level of english language speaking anxiety. Integr. Educ. 24, 98-110. doi: 10.15507/1991-9468.098.024.202001.098-110

Liao, H.-C., and Wang, Y.-H. (2015). Creating a positive learning environment for students with english classroom anxiety. Psychol. Rep. Sociocult. Issues Psychol. 116, 631-646. doi: 10.2466/11.PR0.116k21w8

Liu, M. (2009). Reticence and Anxiety in Oral English Lessons. Berne: Peter Lang Publishing.

Liu, M., Huang, Y., and Xu, Y. (2018). Effects of individual versus group work on learner autonomy and emotion in digital storytelling. Educ. Technol. Res. Dev. 66, 1009-1028. doi: 10.1007/s11423-018-9601-2

Lucas, J. (1984). Communication apprehension in the ESL classroom: getting our students to talk. For. Lang. Ann. 17, 593-598. doi: 10.1111/j.1944-9720.1984. tb01748.x

MacIntyre, P., and Gregersen, T. (2012). Emotions that facilitate language learning: the positive-broadening power of the imagination. Stud. Sec. Lang. Learn. Teach. 2, 193-213.

MacIntyre, P. D. (1999). "Language anxiety: a review of the research for language teachers," in Affect in Foreign Language and Second Language Teaching: A Practical Guide to Creating a Low-Anxiety Classroom Atmosphere, ed. D. J. Young (Boston, MA: McGraw-Hill), 24-45.

MacIntyre, P. D. (2017). "An overview of language anxiety research and trends in its development," in New Insights into Language Anxiety: Theory, Research and Educational Implications, eds C. Gkonou, M. Daubney, and J. M. Dewaele (Bristol: Multilingual Matters), 11-30.

MacIntyre, P. D., Gregersen, T., and Mercer, S. (2019). Setting an agenda for positive psychology in SLA: theory, practice, and research. Modern Lang. J. 103, 262-274.

Mays, N., Pope, C., and Popay, J. (2005). Systematically reviewing qualitative and quantitative evidence to inform management and policy-making in the health field. J. Health Serv. Res. Policy 10(Suppl. 1), 6-20.

Melchor-Couto, S. (2017). Foreign language anxiety levels in second life oral interaction. ReCALL 29, 99-119. doi: 10.1017/S0958344016000185 
Moher, D., Liberati, A., Tetzlaff, J., Altman, D. G., and The Prisma Group. (2009). Preferred reporting items for systematic reviews and meta-analyses: the PRISMA statement. PLoS Med. 6:e1000097. doi: 10.1371/journal.pmed.1000097

Mostafavi, F., and Vahdany, F. (2016). The effect of explicit affective strategy training on Iranian EFL learners' oral language proficiency and anxiety reduction. Adv. Lang. Liter. Stud. 7, 197-210. doi: 10.7575/aiac.alls.v.7n.4p.197

Nosratinia, M., and Abdi, F. (2017). The comparative effect of portfolio and summative assessments on EFL learners' writing ability, anxiety, and autonomy. J. Lang. Teach. Res. 8, 823-834. doi: 10.17507/jltr.0804.24

Oxford, R. (1990). Language Learning Strategies: What Every Teacher Should Know. New York, NY: Newbury House.

Oxford, R. (1997). Cooperative learning, collaborative learning, and interaction: three communicative strands in the language classroom. Modern Lang. J. 81, 443-456. doi: 10.2307/328888

Oxford, R. L. (2011). Teaching \& Researching: Language Learning Strategies. London: Pearson Education Limited.

Oxford, R. L. (2015). Emotion as the amplifier and the primary motive: some theories of emotion with relevance to language learning. Stud. Sec. Lang. Learn. Teach. 5, 371-393. doi: 10.14746/ssllt.2015.5.3.2

Oxford, R. L. (2017b). Teaching and Researching Language Learning Strategies: Self-Regulation Context, 2nd Edn. New York, NY: Routledge.

Oxford, R. L. (2017a). "Anxious language learners can change their minds: ideas and strategies from traditional psychology and positive psychology," in New Insights into Language Anxiety: Theory, Research and Educational Implications, eds C. Gkonou, M. Daubney, and J.-M. Dewaele (Bristol: Multilingual Matters), 179-199.

Phillips, E. M. (1998). “Decreasing language anxiety: practical techniques for oral activities," in Affect in Foreign Language and Second Language: A Practical Guide to Creating a Low-Anxiety Classroom Atmosphere, ed. D. J. Young (New York, NY: McGraw-Hill), 124-143.

Pluye, P., and Hong, Q. N. (2014). Combining the power of stories and the power of numbers: mixed methods research and mixed studies reviews. Annu. Rev. Public Health 35, 29-45. doi: 10.1146/annurev-publhealth-032013-182440

Popay, J., Roberts, H., Sowden, A., Petticrew, M., Arai, L., Rodgers, M., et al. (2006). Guidance on the Conduct of Narrative Synthesis in Systematic Reviews. A Product From the ESRC Methods Programme (Version 1). Lancaster: Lancaster University.

Resurrección, D. M., Salguero, J. M., and Ruiz-Aranda, D. (2014). Emotional intelligence and psychological maladjustment in adolescence: a systematic review. J. Adolesc. 17, 461-472. doi: 10.1016/j.adolescence.2014.03.012

Sağlamel, H., and Kayaoğlu, M. N. (2013). Creative drama: a possible way to alleviate foreign language anxiety. RELC J. 44, 377-394. doi: 10.1177/ 0033688213500597

Scida, E. E., and Jones, J. N. (2017). The impact of contemplative practices on foreign language anxiety and learning. Stud. Sec. Lang. Learn. Teach. 7, 573-599. doi: 10.14746/ssllt.2017.7.4.2

Shimbo, K. (2008). The effects of music, relaxation and suggestion on tertiary students' affect and achievement in learning Japanese as a foreign language. Austr. Rev. Appl. Ling. 31, 16.1-16.22. doi: 10.2104/ara10816

Siddaway, A. P., Wood, A. M., and Hedges, L. V. (2019). How to do a systematic review: a best practice guide for conducting and reporting narrative reviews, meta-analyses, and meta-syntheses. Annu. Rev. Psychol. 70, 747-770. doi: 10. 1146/annurev-psych-010418-102803

Soleimanirad, N., and Shangarffam, N. (2016). The effect of collaborative reasoning discussion on EFL learners' anxiety. Theory Pract. Lang. Stud. 6, 337-346. doi: $10.17507 /$ tpls.0602.15

Tang, L. (2016). Formative assessment in oral English classroom and alleviation of speaking apprehension. Theory Pract. Lang. Stud. 6, 751-756. doi: 10.17507/ tpls.0604.12
Teimouri, Y., Goetze, J., and Plonsky, L. (2019). Second language anxiety and achievement. Stud. Sec. Lang. Acquisit. 41, 363-387. doi: 10.1017/ S0272263118000311

Toyama, M., and Yamazaki, Y. (2019). Anxiety reduction session in foreign language classroom. Lang. Learn. J. 1-13. doi: 10.1080/09571736.2019.1598474 [Epub ahead of print].

Tsiplakides, I. K., and Keramida, A. (2009). Helping students overcome foreign language speaking anxiety in the English classroom: theoretical issues and practical recommendations. Int. Educ. Stud. 2, 39-44.

Tsiriotakis, I. K., Vassilaki, E., Spantidakis, I., and Stavrou, A. M. (2017). The examination of the effects of writing strategy-based procedural facilitative environments on students' English foreign language writing anxiety levels. Front. Psychol. 7:2074. doi: 10.3389/fpsyg.2016.02074

Uştuk, O., and Aydın, S. (2018). The effects of the use of paralinguistic cues on foreign language anxiety among English as a foreign language speakers. Innov. Lang. Learn. Teach. 12, 289-302. doi: 10.1080/17501229.2016. 1211133

Wei, C.-W., Kao, H.-Y., Lu, H.-H., and Liu, Y. C. (2018). The effects of competitive gaming scenarios and personalized assistance strategies on English vocabulary learning. Educ. Technol. Soc. 21, 146-158.

Woodrow, L. (2006). Anxiety and speaking English as a second language. Reg. Lang. Centre J. 37, 308-328. doi: 10.1177/0033688206071315

Xiangming, L., Liu, M., and Zhang, C. (2020). Technological impact on language anxiety dynamic. Comp. Educ. 150, 1-12. doi: 10.1016/j.compedu.2020.103839

Yayli, D. (2017). Using group work as remedy for EFL teacher candidates' listening anxiety. Eur. J. Educ. Res. 71, 41-58. doi: 10.14689/ejer.2017.71.3

York, J., Shibata, K., Tokutake, H., and Nakayama, H. (2020). Effect of SCMC on foreign language anxiety and learning experience: a comparison of voice, video, and VR-based oral interaction. ReCALL 33, 1-22. doi: 10.1017/ S0958344020000154

Young, D. J. (1990). An investigation of students' perspectives on anxiety and speaking. For. Lang. Ann. 23, 539-553. doi: 10.1111/j.1944-9720.1990.tb00 424.x

Young, D. J. (1992). Language anxiety from the foreign language specialist's perspective: interviews with Krashen, Omaggio Hadley, Terrell and Radin. For. Lang. Ann. 25, 157-172. doi: 10.1111/j.1944-9720.1992.tb00 524.x

Yu, L.-T., Song, J., and Chiu, F.-Y. (2020). Using a three-dimension virtual world to reduce language anxiety and enhance English-speaking performance of EFL university learners: a collaborative project. Taiwan J. TESOL 17, 65-89. doi: 10.30397/TJTESOL.202010_17(2).0003

Zarrinabadi, N., and Rezazadeh, M. (2020). Why only feedback? Including feed up and feed forward improves non-linguistic aspects of L2 writing. Lang. Teach. Res. [Epub ahead of print]. doi: 10.1177/1362168820960725

Zhang, X. (2019). Foreign language anxiety and foreign language performance: a meta-analysis. Modern Lang. J. 103, 763-781. doi: 10.1111/modl. 12590

Conflict of Interest: The authors declare that the research was conducted in the absence of any commercial or financial relationships that could be construed as a potential conflict of interest.

Copyright (c) 2021 Toyama and Yamazaki. This is an open-access article distributed under the terms of the Creative Commons Attribution License (CC BY). The use, distribution or reproduction in other forums is permitted, provided the original author(s) and the copyright owner(s) are credited and that the original publication in this journal is cited, in accordance with accepted academic practice. No use, distribution or reproduction is permitted which does not comply with these terms. 